MEDIKA ALKHAIRAAT : JURNAL PENELITIAN KEDOKTERAN DAN KESEHATAN 2(3): 100-108

e-ISSN: 2656-7822, p-ISSN: 2657-179X

\title{
GAMBARAN RESPONSE TIME DAN KARAKTERISTIK PETUGAS IGD RSU ANUTAPURA PALU TAHUN 2019
}

\author{
Dwi St Nashrah Azia ${ }^{1}$, Sitti Atikah" ${ }^{2 *}$, Andi Meutiah Ilhamjaya ${ }^{2}$ \\ ${ }^{1,2}$ Fakultas Kedokteran Universitas Alkhairaat, Palu, Sulawesi Tengah, Indonesia \\ ${ }^{2 *}$ Unit Transfusi Darah, RSU. Anutapura Palu, Sulawesi Tengah, Indonesia \\ *Corresponding author: Telp: +62 877-4013-9468 email: dwistnashrah@ gmail.com
}

\begin{abstract}
ABSTRAK
IGD sebagai gerbang utama penanganan kasus gawat darurat di rumah sakit memegang peranan penting dalam upaya penyelamatan hidup klien. Kecepatan dan ketepatan pertolongan yang diberikan pada pasien yang datang ke IGD memerlukan standar baku sehingga dapat menjamin suatu penanganan gawat darurat dengan response time yang cepat dan tepat. Response time yang cepat dan tepat merupakan salah satu penentu kepuasan pasien terhadap pelayanan rumah sakit. Jenis penelitian ini adalah penelitian deskriptif kualitatif, dengan jumlah sampel 100 orang pasien dan 35 orang petugas. Teknik pengumpulan data menggunakan instrument kuesioner, dan teknik analisis data dengan menggunakan uji distribusi frekuensi.

Sebanyak 94 pasien (95\%) memperoleh response time baik ( $<5$ bmenit), 4 pasien $(4,0 \%)$ response time cukup (5-10 menit), dan 1 pasien (1,0\%) memperoleh response time buruk (>10 menit). (2) Karakteristik petugas medis di IGD RSU Anutapura berdasarkan jenis kelamin yaitu 20 orang $(57,14 \%)$ laki-laki dan 15 orang $(42,86 \%)$ perempuan. (3) Berdasarkan lama bekerja petugas IGD di RSU Anutapura Palu kategori terbanyak adalah sudah bekerja selama $>5$ tahun yaitu 19 orang (54,29\%), 1-5 tahun sebanyak 10 orang (28,57\%) dan $<1$ tahun sebanyak 6 orang $(17,14 \%)$. (4) Berdasarkan pengalaman pelatihan petugas medis sebanyak 31 orang $(88,57 \%)$ telah mengikuti ATLS/BTLS, ACLS/BCLS serta 4 orang (11,43\%) belum mengikuti pelatihan. (5) Berdasarkan fasilitas penunjang medis di IGD RSU Anutapura Palu, diperoleh 33 orang $(94,29 \%)$ petugas IGD menyatakan terpenuhi dan 2 orang $(5,71 \%)$ menyatakan belum terpenuhi.

Disimpulkan bahwa ditemukan sebanyak 95 pasien $(95 \%)$ mendapatkan response time baik $(\leq 5$ menit), hal ini ditunjang dengan karakteristik petugas medis di IGD RSU Anutapura berdasarkan jenis kelamin terbanyak adalah laki-laki yaitu 20 orang $(57,14 \%)$ dengan 19 orang $(54,29 \%)$ diantaranya sudah bekerja selama $>5$ tahun serta 31 orang $(88,57 \%)$ petugas medis telah mengikuti pelatihan, ditambah lagi kecepatan waktu tanggap (response time) petugas medis ditunjang dengan fasilitas medis di IGD RSU Anutapura Palu yang tergolong memadai dibuktikan dari 33 orang (94,29\%) petugas medis di IGD menyatakan terpenuhi dengan fasilitas tersebut.
\end{abstract}

Kata Kunci :Response time, IGD, RSU. Anutapura Palu.

\section{ABSTRACT}

The emergency room as the main gate for handling emergency cases in the hospital plays an important role in saving clients' lives. The speed and accuracy of the assistance provided to patients who come to the emergency room require standard standards so that it can guarantee an emergency treatment with a fast and precise response time. Fast and precise response time is one of the determinants of patient satisfaction with hospital services. This type of research is a qualitative descriptive study, with a sample of 100 patients and 35 officers. Data collection techniques using questionnaire instruments, and data analysis techniques using frequency distribution tests. 
MEDIKA ALKHAIRAAT : JURNAL PENELITIAN KEDOKTERAN DAN KESEHATAN 2(3): 100-108

e-ISSN: 2656-7822, p-ISSN: 2657-179X

A total of 94 patients (95\%) received good response time ( $<5 \mathrm{~min}), 4$ patients $(4.0 \%)$ had adequate response time (5-10 minutes), and 1 patient (1.0\%) received a bad response time (>10 minutes). (2) Characteristics of medical officers in Anutapura General Hospital emergency room based on sex, namely 20 people (57.14\%) male and 15 people (42.86\%) women. (3) Based on the length of work of emergency room staff at Anutapura Hospital in Palu, the most categories have been working for $>5$ years, namely 19 people (54.29\%), 1-5 years as many as 10 people (28.57\%) and <1 year as many as 6 people (17.14\%). (4) Based on the training experience of medical staff, 31 people (88.57\%) had participated in ATLS / BTLS, ACLS / BCLS and 4 people (11.43\%) had not attended training. (5) Based on medical support facilities in Anutapura General Hospital Palu, 33 people (94.29\%) of emergency room staff stated that they were fulfilled and 2 people $(5.71 \%)$ stated that they were not fulfilled.

Conclusion: It was found that as many as 95 patients (95\%) had good response time ( $\leq 5$ minutes), this was supported by the characteristics of medical staff in Anutapura General Hospital emergency room based on the most sexes, namely 20 males (57.14\%) with 19 people (54.29\%) of them have worked for $>5$ years and 31 people $(88.57 \%)$ medical officers have attended training, plus the speed of response time (response time) of medical staff is supported by medical facilities in IGD Anutapura Hospital, Palu which classified as adequate as evidenced from 33 people (94.29\%) medical officers in the emergency room stated fulfilled with these facilities.

Keywords: Response time, ER, RSU. Anutapura Palu.

\section{PENDAHULUAN}

IGD sebagai gerbang utama penanganan kasus gawat darurat di rumah sakit memegang peranan penting dalam upaya penyelamatan hidup klien. Kecepatan dan ketepatan pertolongan yang diberikan pada pasien yang datang ke IGD memerlukan standar sesuai dengan kompetensi dan kemampuannya sehingga dapat menjamin suatu penanganan gawat darurat dengan response time yang cepat dan penanganan yang tepat. (Keputusan menteri kesehatan, 2009)

Konteks pelayanan kegawatdaruratan merupakan aspek terpenting pada tahap pelaksanaan/implementasi yang mengacu kepada dasar pelayanan gawat darurat yaitu time saving is life saving (waktu adalah nyawa) dengan ukuran keberhasilan adalah response time (waktu tanggap) selama 3 menit dan waktu definitife $\leq 2$ jam (dihitung sejak pasien datang sampai dilakukan penanganan. (Suhartati dkk, 2011; Basoeki dkk, 2008)

Response time merupakan hal yang sangat penting karena berkaitan dengan cepat atau lamanya pasien mendapatkan pelayanan kesehatan. Keberhasilan waktu tanggap atau response time sangat tergantung kepada kecepatan yang tersedia serta kualitas pemberian pertolongan untuk menyelamatkan nyawa atau mencegah cacat sejak di tempat kejadian, dalam perjalanan hingga pertolongan rumah sakit., sehingga response time yang cepat dan tepat merupakan salah satu penentu kepuasan pasien terhadap pelayanan rumah sakit. (Moewardi, 2003) Response time yang cepat dan penanganan yang tepat dapat dicapai dengan meningkatkan sarana, prasarana, sumberdaya manusia, dan manajemen IGD rumah sakit sesuai dengan standar. (Keputusan menteri kesehatan, 2009)

RSU. Anutapura Palu adalah rumah sakit tipe B yang menyediakan fasilitas pelayanan spesialistik yang luas dan pelayanan subspesialistik tertentu. RSU Anutapura Palu sebagai salah satu rumah sakit yang diselenggarakan oleh Pemerintahan Kota, yang menjadi salah satu rumah sakit rujukan dan juga sebagai rumah sakit pendidikan mahasiswa kedokteran di Kota Palu, sehingga sangat menarik untuk menjadi lokasi penelitian bidang pelayanan kesehatan. Berdasarkan data yang diperoleh dari rekam medik RSU Anutapura Palu, data kunjungan pasien di Instalasi Gawat Darurat RSU Anutapura Palu tahun 2016 - 2017 
MEDIKA ALKHAIRAAT : JURNAL PENELITIAN KEDOKTERAN DAN KESEHATAN 2(3): 100-108

e-ISSN: 2656-7822, p-ISSN: 2657-179X

mengalami penurunan yaitu 8933 - 7687 pasien. Deskripsi jenis pelayanan pada kasus non bedah, tingkat kematiannya lebih tinggi dibanding kasus bedah pada pelayanan Instalasi Gawat Darurat RSU Anutapura Palu sebelum dirawat. (Data primer RSU Anutapura Palu, 2018)

\section{METODOLOGI}

\section{Jenis dan Rencana Penelitian}

Penelitian ini merupakan penelitian deskriptif kualitatif dengan pendekatan cross sectional study pada 100 orang pasien dan 35 orang petugas medis di IGD RSU Anutapura Palu Tahun 2019.

\section{Waktu dan Tempat Penelitian}

1. Waktu Penelitian

Waktu penelitian adalah jangka waktu yang dibutuhkan penulis untuk memperoleh data studi kasus yang dilaksanakan. Penelitian ini dilaksanakan pada tanggal 15 Juli - 11 Oktober 2019.

\section{Tempat Penelitian}

Tempat Penelitian adalah tempat yang digunakan untuk pengambil data selama kasus berlangsung. Pengambilan sampel penelitian dilakukan di IGD RSU Anutapura Palu.

Populasi, Sampel dan Teknik Pengambilan Sampel

1. Populasi

Populasi adalah keseluruhan obyek penelitian yang memiliki karakteristik tertentu yang ditetapkan oleh peneliti untuk di pelajari kemudian ditarik kesimpulannya. Populasi dalam penelitian ini adalah setiap pasien baru masuk di IGD RSU Anutapura Palu periode Juli sampai Oktober 2019 dan seluruh petugas di IGD RSU Anutapura Palu.

2. Sampel

Sampel dalam penelitian ini adalah sebagian pasien baru masuk IGD RSU Anutapura Palu sebanyak 100 orang yang ditentukan melalui rumus Slovin dan petugas IGD sebanyak 35 petugas.

$$
n=\frac{\mathrm{N}}{1+\mathrm{N}\left(\mathrm{e}^{2}\right)}
$$

Keterangan :

$\mathrm{N}$ : Besar Populasi

$\mathrm{n}$ : Besar Sampel

e: Tingkat kepercayaan atau ketetapan yang diinginkan

3. Teknik Pengambilan Sampel

Pengambilan sampel adalah dengan menggunkan teknik convenience sampling. Dimana pada pasien yang dating berobat di IGD RSU Anutaputa Palu dilakukan pengambilan data terhedapnya.

Berikut ini kriteria inklusi sampel pasien IGD.

1. Pasien yang baru masuk IGD RSU Anutapura Palu

Berikut ini kriteria eklusi sampel penelitian :

1. Pasien/keluarga menolak menandatangani informed consent.

2. Pasien dalam kondisi tidak sadar/koma (tidak kooperatif).

\section{Ruang Lingkup Penelitian}

Ruang lingkup penelitian ini mencakup tentang response time dan karakteristik petugas IGD RSU Anutapura Palu.

\section{Metode Pengumpulan Data}

Data sekunder di peroleh dari data yang dimiliki RSU Anutapura Palu.

Data primer di peroleh dari hasil interview langsung dengan menandatangani pasien atau wali pasien untuk mendapatkan informasi lebih rinci dan melalui wawancara dengan menggunakan kuesioner. 
MEDIKA ALKHAIRAAT : JURNAL PENELITIAN KEDOKTERAN DAN KESEHATAN 2(3): 100-108

e-ISSN: 2656-7822, p-ISSN: 2657-179X

\section{Analisa Data}

Data pada penelitian ini diolah menggunakan aplikasi SPSS 25.0 adapun analisis statistik yang digunakan adalah deskriptif dengan melakukan perhitungan statistik sederhana. Untuk skala nominal dapat dihitung frekuensi dan presentase atau rate. Hasilnya berupa frekuensi dan presentasi yang disajikan dalam bentuk tabel.

\section{HASIL DAN PEMBAHASAN}

HASIL

Penelitian ini dilakukan di IGD RSU Anutapura Palu pada bulan Juli sampai Oktober tahun 2019 terhadap 100 pasien yang datang berobat di IGD RSU Anutapura Palu. Pengambilan data dilakukan dengan wawancara langsung menggunakan kuesioner. Hasil analisa statistik ditampilkan dengan sistematika sebagai berikut:

1. Gambaran response time pelayanan pasien yang dating berobat di IGD RSU Anutapura Palu 2019

Tabel 1 Distribusi frekuensi berdasarkan response time pasien di IGD RSU Anutapura Palu tahun 2019

\begin{tabular}{|c|c|c|}
\hline Response Time & $\mathrm{n}$ & $\%$ \\
\hline Buruk & 1 & 1,0 \\
\hline Cukup & 4 & 4,0 \\
\hline Baik & 95 & 95,0 \\
\hline Total & 100 & 100 \\
\hline
\end{tabular}

Sumber : Data Primer (2019)

Tabel 1 di atas menunjukkan bahwa dari 100 pasien IGD RSU Anutapura Palu yang telah mengisi kuesioner, diperoleh 95 orang (95\%) yang menyatakan bahwa response time pelayanan IGD tersebut tergolong baik, 4 orang (4\%) menyatakan bahwa response time pelayan IGD tersebut tergolong cukup, dan selebihnya hanya 1 orang (1\%) yang menyatakan response time pelayanan IGD tersebut tergolong buruk.

2. Gambaran karakteristik petugas di IGD RSU Anutapura Palu tahun 2019
Tabel 2 Distribusi frekuensi karakteristik petugas di IGD RSU Anutapura Palu tahun 2019

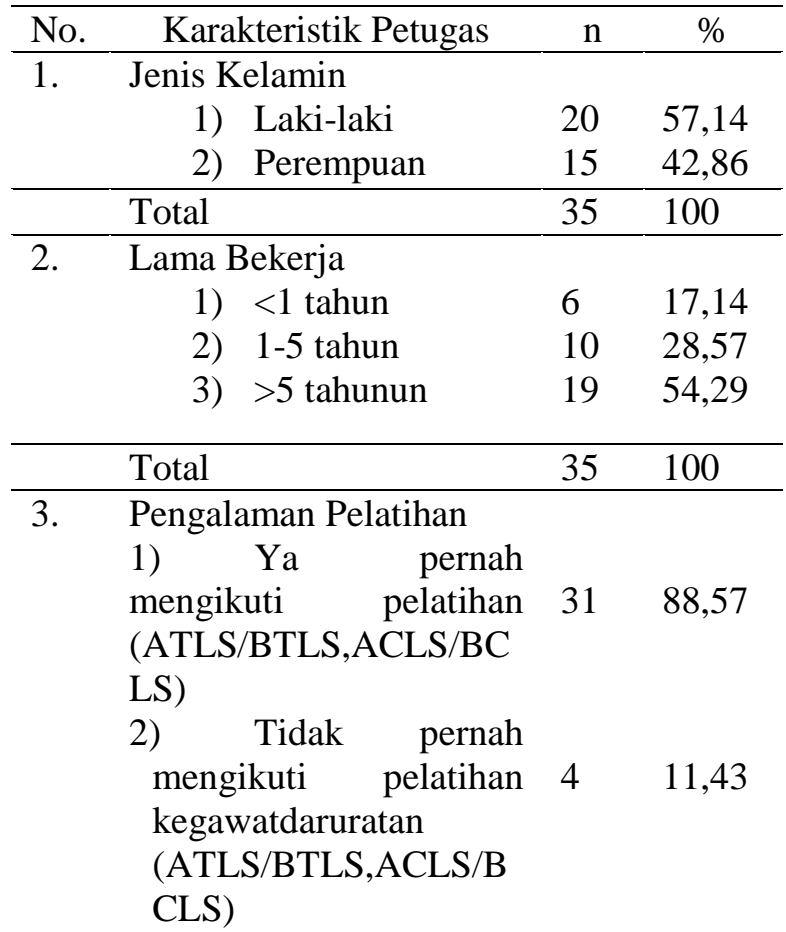

\begin{tabular}{llrl}
\hline & Total & 35 & 100 \\
\hline 4. & $\begin{array}{l}\text { Ketersediaan fasilitas } \\
\text { medis yang menunjang di }\end{array}$ & \\
& &
\end{tabular}

IGD

\begin{tabular}{llll} 
1) & Iya ada & 33 & 94,29 \\
2) & Tidak ada & 2 & 5,71 \\
\hline & Total & 35 & 100 \\
\hline
\end{tabular}

Sumber : Data Primer (2019)

Tabel 2 di atas menunjukkan bahwa terdapat 35 orang petugas IGD RSU Anutapura Palu, yang mana 20 orang diantaranya $(57,14 \%)$ adalah laki-laki dan 15 orang lainnya $(42,86 \%)$ adalah perempuan.

Dari total 35 orang petugas IGD RSU Anutapura Palu, diperoleh 19 orang (54,29\%) petugas yang telah bekerja di IGD lebih dari 5 tahun, 10 orang $(28,57 \%)$ petugas yang bekerja di IGD selama kurun waktu 1 sampai 5 tahun, sedangkan sisanya 6 orang $(17,14 \%)$ baru bekerja di IGD kurang dari 1 tahun.

Dari total 35 orang petugas IGD tersebut, 31 orang $(88,57 \%)$ diantaranya sudah pernah mengikuti pelatihan kegawatdaruratan 
MEDIKA ALKHAIRAAT : JURNAL PENELITIAN KEDOKTERAN DAN KESEHATAN 2(3): 100-108

e-ISSN: 2656-7822, p-ISSN: 2657-179X

sedangkan 4 orang lainnya $(11,43 \%)$ belum pernah mengikuti pelatihan kegawatdaruratan.

Dari 35 orang petugas IGD RSU Anutapura Palu, diperoleh 33 orang petugas $(94,29 \%)$ yang menyatakan fasilitas medis penunjang tersedia di IGD, selebihnya yakni 2 orang $(5,71 \%)$ menyatakan bahwa fasilitas medis penunjang tidak tersedia di IGD RSU Anutapura Palu.

PEMBAHASAN

Adapun hasil dari penelitian :

\section{Response time}

Penelitian ini merupakan penelitian deskriptif dengan pendekatan Cross Sectional study yang dilakukan pada pasien baru yang masuk di IGD RSU Anutapura Palu selama periode Juli - Oktober 2019. Ternyata, hasil menunjukkan bahwa dari 100 orang pasien baru masuk di IGD RSU Anutapura Palu periode Juli-Oktober 2019, terdapat sebanyak 95 orang (95\%) pasien menyatakan bahwa response time pelayanan IGD RSU Anutapura Palu tergolong baik ( $<5$ menit) terdapat 4 orang (4\%) menyatakan response time tergolong cukup (510 menit), dan hanya 1 orang (1\%) yang menyatakan response time pelayanan tergolong buruk.

Dari hasil tersebut menunjukkan bahwa response time pelayanan di IGD RSU Anutapura Palu sebagian besar sudah tergolong baik (response time pelayanan $<5$ menit). Keadaan ini menunjukkan bahwa IGD RSU Anutapura Palu telah memenuhi standar pelayanan IGD sesuai keputusan Menteri Kesehatan Republik Indonesia nomor 856 tahun 2009.

Hal ini sejalan dengan penelitian yang dilakukan oleh Marioi et al pada tahun 2015 di IGD RSU GMIM Kalooraan Amurang, dimana dari 69 responden, ada 36 responden $(52,2 \%)$ yang mendapatkan response time yang cepat $(<5$ menit) dan 33 responden $(47,85 \%)$ yang mendapatkan response time yang lambat $(>5$ menit). (Marioi et al. 2015)

Hasil penelitian lainnya yang dilakukan oleh Eko Widodo pada tahun 2015 di IGD RS.
Panti Waluyo Sukarto,terhadap 95 orang pasien diperoleh sebanyak 70 pasien $(73,7 \%)$ yang mendapatkan response time sangat cepat yakni dengan response time < 3 menit. (Eko W, 2015)

Hal ini hampir senada dengan penelitian ini oleh karena response time pada pelayanan di IGD Rumah Sakit di Indonesia telah diatur dan diharapkan sesuai dengan keputusan Menteri Kesehatan Republik Indonesia nomor 856 tahun 2009 yang mana diketahui bahwa kategori untuk menyatakan response time yang tergolong baik adalah < 5 menit. Sehingga dapat disimpulkan bahwan pelayanan medis di IGD RSU Anutapura Palu tahun 2019 tergolong cepat dan memenuhi standar pelayanan IGD.

\section{Karakteristik petugas IGD berdasarkan Jenis kelamin}

Berdasarkan hasil penelitian yang telah dilakukan di IGD RSU Anutapura Palu tahun 2019 diketahui bahwa petugas terbanyak adalah berjenis kelamin laki-laki yakni 20 orang $(57,14 \%)$ sedangkan petugas perempuan berjumlah 15 orang $(42,86 \%)$.

Pada penelitian yang dilakukan oleh Sahrul S dan Andi M pada tahun 2016 terkait dengan hubungan antara beban kerja perawat dengan respon time pada penanganan pasien di IGD RS Ibnu Sina Makassar justru didapati distribusi frekuensi perawat yang berjumlah 21 orang dengan jenis kelamin terbanyak adalah perawat perempuan yaitu 16 orang $(76,2 \%)$ dan perawat laki-laki sebanyak 5 orang $(23,8 \%)$ (Sahrul S, \&Andi M., 2016).

Hal yang sama juga dijelaskan pada penelitian yang dilakukan oleh Rima dan Reginus T pada tahun 2015 di IGD RSUP Prof. DR. R. D. Kandon Manado pada distribusi frekuesi perawat yang berjumlah 40 orang dengan 24 orang $(60 \%)$ diantaranya berjenis kelamin perempuan dan 16 orang (40\%) berjenis kelamin laki-laki (Rima Wahyu A.M, \&Reginus T.M, 2015).

Begitu pula penelitian yang dilakukan oleh Ilyas pada tahun 2001 yang menyatakan perbedaan jenis kelamin memiliki dorongan yang berbeda, dimana mereka dengan jenis 
kelamin laki-laki memiliki dorongan lebih besar dari pada perempuan karena tanggung jawab laki-laki lebih besar, tetapi dari perbedaan itu tidak serta merta dapat berpengaruh besar terhadap response time di IGD oleh karena perempuan lebih memiliki tingkat ketelitian dan kehati-hatian dalam penanganan pasien dibandingkan dengan petugas berjenis kelamin laki-laki, selain itu perempuan cenderung lebih mematuhi peraturan yang berlaku dibandingkan dengan petugas laki-laki, misalnya terkait dengan jam kerja.

Senada dengan hasil penelitian ini, dimana diperoleh karakteristik petugas medis di IGD RSU Anutapura Palu terbanyak adalah laki-laki yaitu 20 orang $(57,14 \%)$, hal tersebut dimungkinkan oleh karena petugas medis lakilaki lebih memiliki peran serta porsi kerja yang lebih besar dibandingkan petugas medis perempuan, walaupun demikian perbedaan jenis kelamin laki-laki dan perempuan tidak memiliki pengaruh signifikan terkait dengan kinerja seorang petugas medis.

\section{Karakteristik petugas IGD berdasarkan Lama bekerja}

Berdasarkan hasil penelitian yang telah dilakukan di IGD RSU Anutapura Palu tahun 2019 terkait lama bekerja petugas medis kategori terbanyak yaitu > 5 tahun dengan jumlah petugas sebanyak 19 orang $(54,29 \%)$, kategori 1 - 5 tahun sebanyak 10 orang $(28,57 \%)$, sedangkan kategori $<1$ tahun terdapat 6 orang $(17,14 \%)$.

Berkaitan dengan lama bekerja petugas medis di IGD, juga dijelaskan pada penelitian yang dilakukan oleh Sahrul S dan Andii M pada tahun 2016 melalui analisa univariat distribusi frekuensi karakteristik responden perawat yang terdiri dari 21 orang ditemukan lama bekerja terbanyak adalah responden yang telah bekerja selama 5-8 tahun yaitu sebanyak 8 orang $(38,1 \%)$ dan 6 orang $(28,6 \%)$ diantara telah bekerja selama 2-4 tahun. Hal tersebut dalam penelitiannya disimpulkan bahwa kematangan individu dapat dilihat secara objektif, dimana tingkat kematangan dalam berpikir dan berperilaku dipengaruhi oleh pengalaman kehidupan sehari-hari, semakin lama masa kerja maka semakin tinggi pula tingkat kematangan seseorang dalam berpikir sehingga dapat lebih meningkatkan pengetahuan yang dimilikinya. Seseorang dengan masa kerja paling lama khususnya di IGD tentu memiliki banyak pengalaman terkait dengan masalah atau kasuskasus kegawatdaruratan, sehingga sangat baik pengaruhnya terhadap response time. (Sahrul S,\& Andi M. 2016)

Hal ini sejalan dengan penelitian yang dilakukan oleh Ariawan Gede pada tahun 2018 bahwa petugas yang masa kerjanya lebih dari 10 tahun lebih mempunyai pengalaman dan pengetahuan yang memadai, serta sudah banyak mengetahui kondisi dan persoalan-persoalan yang terjadi di masa kerja. (Ariawan, 2018)

Pada penelitian ini didapati hasil bahwa karakteristik petugas medis di IGD RSU Anutapura Palu berdasarkan lama bekerjanya didapati hasil terbanyak yaitu pada petugas medis dengan lama bekerja > 5 tahun. Hal tersebut dimungkinkan karena untuk kecepatan response time pelayanan pasien di IGD juga dibutuhkan pengalaman pelayanan petugas medis yang sudah berkompeten dan juga telah menangani banyak pasien baik di IGD maupun di ruang rawat inap rumah sakit.

\section{Karakteristik petugas IGD berdasarkan pengalaman pelatihan \\ Pada penelitian yang telah dilakukan di} IGD RSU Anutapura Palu tahun 2019 terkait distribusi karakteristik petugas medis berdasarkan pengalaman pelatihan terdapat sebanyak 31 orang $(88,57 \%)$ yang telah mengikuti pelatihan kegawatdaruratan dan terdapat 4 orang $(11,43)$ belum mengikuti pelatihan.

Terkait dengan hubungan antara response time dengan pengalaman pelatihan petugas medis di IGD rumah sakit, telah dilakukan penelitian oleh Annisa P.G pada tahun 2018 mengenai gambaran pendidikan, pelatihan, dan lama kerja terhadap pengetahuan perawat di IGD RSUD Deli Serdang Tahun 2017 
didapatkan hasil distribusi frekuensi karakteristik perawat berdasarkan pengalaman pelatihan yang terdiri dari 25 orang terbagi atas 14 orang $(56 \%)$ yang telah mengikuti pelatihan BCLS/BTLS/PPGD tergolong dalam responden dengan pengetahuan tinggi dan 11 orang (44\%) yang belum pernah mengikuti pelatihan tergolong dalam kriteria responden dengan pengetahuan rendah, hasil tersebut disimpulkan bahwa pelatihan petugas medis dapat menambah pengetahuan dan skill seorang petugas medis dalam memberikan penanganan medis terhadap pasien pada keadaan gawat darurat. Dalam penelitian yang dilakukan Annisa P.G pada tahun 2018 menyatakan pelatihan penanggulangan penderita gawat darurat merupakan pelatihan yang menyangkut pengetahuan dan keterampilan untuk penanganan pertama dalam menghadapi kegawatdaruratan serta ditujukan bagi tenaga kesehatan baik dokter maupun perawat. (Annisa P.G, 2018)

Menurut teori dari American College of Emergency Physician pada tahun 2008, ketersediaan sumber daya manusia yang kompeten dapat mendukung tercapainya response time yang baik.

Sejalan dengan teori tersebut, pada penelitian ini didapati hasil bahwa pengalaman pelatihan yang telah diikuti oleh petugas sebanyak 31 orang $(88,57 \%)$ menunjukkan bahwa petugas medis di IGD RSU Anutapura Palu memiliki tingkat pengetahuan yang sesuai dengan kompetensi yang dibutuhkan dalam mendukung tercapainya response time di IGD.

\section{Karakteristik petugas IGD berdasarkan ketersediaan fasilitas medis yang menunjang}

Berdasarkan hasil penelitian yang telah dilakukan di IGD RSU Anutapura Palu tahun 2019 ketersediaan fasilitas medis yang menunjang kinerja petugas maka diperoleh 33 orang petugas $(94,29 \%)$ yang menyebutkan bahwa fasilitas medis telah terpenuhi dan 2 orang $(5,71 \%)$ menyebutkan belum terpenuhi terkait fasilitas medis.
Sejalan dengan penelitian yang dilakukan Sabriyanti I pada tahun 2012 yang mendapatkan hasil bahwa ketersediaan stretcher dapat memiliki pengaruh 9,217 kali dan 1,995 kali terhadap ketepatan response time di IGD bedah maupun non-bedah RSUP Dr. Wahidin Sudirohusodo. Hal ini berarti dengan pemenuhan fasilitas IGD di rumah sakit dapat sangat membantu dalam mempersingkat response time pelayanan.

Dari hasil diatas dapat disimpulkan bahwa IGD RSU Anutapura Palu sudah meningkatkan mutu pelayanan di IGD dengan terpenuhinya sarana dan prasarana dalam membangun sistem manajemen IGD yang baik dalam mencapai Standar Pelayanan Minimal. Namun, hasil dari penelitian ini masih pelu dikaji lebih mendalam terkait faktor-faktor yang dapat mempengaruhi ketepatan response timedi IGD RSU Anutapura Palu.

Menurut teori Green, et.al pada tahun 2006 yang mengemukakan selain ketersediaan sarana dan prasarana di IGD perlu diadakan penempatan staf yang sesuai karena sangat berdampak pada keterlambatan penanganan di IGD atau sangat mempengaruhi respon time.

\section{KESIMPULAN}

Berdasarkan hasil penelitian tentang gambaran response time dan karakteristik petugas di IGD RSU Anutapura Palu tahun 2019, dapat disimpulkan sebagai berikut:

1. Response time dalam memberikan pelayanan di IGD RSU Anutapura Palu memiliki kategori baik atau pelayanannya sangat cepat $<5$ menit $(95,0 \%)$, kategorik cukup 5-10 menit (4\%), kategorik buruk > 10 menit (1\%).

2. Karakteristik petugas IGD RSU Anutapura Palu berdasarkan jenis kelamin terbanyak laki-laki sebanyak 20 orang $(57,14 \%)$, dan perempuan 15 orang $(42,86 \%)$.

3. Karakteristik petugas IGD RSU Anutapura Palu berdasarkan lama bekerja 
MEDIKA ALKHAIRAAT : JURNAL PENELITIAN KEDOKTERAN DAN KESEHATAN 2(3): 100-108

e-ISSN: 2656-7822, p-ISSN: 2657-179X

> 5 tahun sebanyak 19 orang $(54,29 \%)$, lama bekerja 1-5 tahun 10 orang $(28,57)$, lama bekerja $<1$ tahun 6 orang $(17,14 \%)$.

4. Karakteristik petugas IGD RSU Anutapura Palu berdasarkan pengalaman mengikuti pelatihan sebanyak 31 orang $(88,57 \%)$, tidak mengikuti pelatihan 4 orang $(11,43)$.

5. Karakteristik petugas IGD RSU Anutapura Palu berdasarkan ketersediaan fasilitas medis yang menunjang di IGD sebanyak 33 orang $(94,29 \%)$, dan 2 orang $(5,71 \%)$ menyatakan fasilitas medis tidak menunjanng.

\section{DAFTAR PUSTAKA}

1. American College of Emergency Physician. (2008) Emergency Department Crowding: High Impact Solution. http:/ebookbrowse.com/emergencydepartment-crowding-high-impactsolutions-acep-task-force-on-boardingapril-2008-pdf-d319291546.

2. Aprianti R.W, Malara R.T. Hubungan Faktor-Faktor Eksternal dengan Response Time Perawat dalam Penanganan Pasien Gawat Darurat di IGD RSUP Prof. DR. R.D. Kandou Manado. ejournal Keperawatan (e-Kp). 2015 Mei. 3(2):2-5

3. Blanchard IE. Doig CJ. Hagel BE. Anton AR. Zygun DA. Kortbeek JB. Et all tahun 2012. Emergency medical services response time and mortality in an urban setting. Prehospital emergency care. 2012;16:142-151.

4. Departemen kesehatan. 2013. Pedoman penyelenggaraan pelayanan rumah sakit. Jakarta: kementrian kesehatan RI.

5. Fadhilah, Harahap WA, Lestari Y. Faktor-faktor yang Berhubungan dengan Waktu Tanggap pada Pelayanan Kasus Kecelakaan Lalu Lintas di Instalasi Gawat Darurat Rumah Sakit Umum Pusat Dr.M. Djamil Padang Tahun 2013. Jurkshan andas. 2015;4(1).
6. Ganida A.P. Gambaran Pendidikan Pelatihan dan Lama Bekerja Terhadap Pengetahuan Perawat di IGD RSUD Deli Serdang Tahun 2017. Repositori Institusi USU. Universitas Sumatra Utara. Semarang: 2018. p. 55-56.

7. Haryatun N, Sudaryanto A. Perbedaan waktu tanggap tindakan keperawatan pasien cedera kepala kategori I-V di Instalasi Gawat Darurat RSUD Dr. Moewardi. Berita Ilmu Keperawatan. 2008;1(2):69-74.

8. Nuzhah.Analisis Response Time pada Pelayanan IGD RSU Anutapura dan RS Undata Palu tahun 2012. Palu: Universitas Alkhairaat. 2012

9. Rembet M.A, Mulyadi, Malara R.T. Hubungan Response Time Perawat dengan Tingkat Kepercayaan Keluarga Pasien pad Triase Kuning (urgent) di Instalasi Gawat Darurat RSU GMIM Kalooran Amurang. Ejournal Keperawatan. Manado: 2015 Sep. 3(2):56

10. Republik Indonesia. Peraturan menteri kesehatan republik indonesia nomor 72 tahun 2016 tentang standar pelayanan kefarmasian di rumah sakit. Menteri kesehatan. Jakarta.

11. Republik Indonesia. 2009. UndangUndang No. 44 Tahun 2009 tentang Rumah Sakit. Lembaran Negara RI Tahun 2009. Menteri kesehatan. Jakarta.

12. Republik Indonesia. Keputusan menteri kesehatan republik Indonesia no 856/menkes/SK/IX/2009. Menteri kesehatan. Jakarta.

13. Republik Indonesia. Peraturan menteri kesehatan republik Indonesia nomor 24 tahun 2016 tentang persyaratan teknis bangunan dan prasarana rumah sakit. Menteri kesehatan. Jakarta.

14. Republik Indonesia. Keputusan menteri kesehatan republik Indonesia no 129/menkes/SK/II/2008 tentang standar pelayanan minimal rumah sakit. Menteri kesehatan. Jakarta. 
MEDIKA ALKHAIRAAT : JURNAL PENELITIAN KEDOKTERAN DAN KESEHATAN 2(3): 100-108

e-ISSN: 2656-7822, p-ISSN: 2657-179X

15. Republik Indonesia. Peraturan menteri kesehatan republik Indonesia nomor 17 tahun 2013 tentang izin dan penyelenggaraan praktik perawat. Jakarta.

16. Republik Indonesia. Peraturan menteri kesehatan republik indonesia nomor 24 tahun 2016 tentang persyaratan teknis bangunan dan prasarana rumah sakit. Jakarta.

17. Sabriyanti N.I,Islam A.A, Gaus S. FaktorFaktor Yang Berhubungan dengan Ketepatan Waktu Tanggap Penanganan Kasus pada Response Time Diinstalasi Gawat Darurat Bedah dan Non-Bedah RSUP DR.Wahidin Sudirohusodo. Makassar: Universitas Hasanuddin. 2012. p. 7-8.

18. Said S, Mappanganro A. Hubungan Beban Kerja Perawat dengan Respon Time pada Penanganan Pasien di Instalasi Gawat Darurat Rumah Sakit Ibnu Sina Makassar. Jurnal of Islamic Nursing. Makassar. 2018;3(1):73-75.

19. World health organization. Hospitals. $2017 . \quad$ Diakses pada: http://www.who.int/hospitals/en/

20. Widodo E. Hubungan Response Time Perawat Dalam Memberikan Pelayanan dengan Kepuasan Pelanggan di IGD RS Panti Waluyo Surakarta. Stikes Kusuma Husada. Surakarta: 2015. p. 38-39.

21. Yoon P. Steiner I. Reinhardt G. Analysis of factor influencing length of stay in the emergency department. Cjem.2003 may. 5(3):155-61. 